Survivor research in Canada: 'Talking' recovery, resisting psychiatry, and reclaiming madness

Author: Danielle Landry

Journal: Disability \& Society, Volume 32, 2017, Issue 9

Pages: 1437-1457

Publisher version DOI: https://doi.org/10.1080/09687599.2017.1322499

\title{
Keywords:
}

survivor research, user-led research, critical discourse analysis, Mad

Studies

\section{Survivor research in Canada: 'Talking' recovery, resisting psychiatry, and reclaiming madness}

\begin{abstract}
Beginning with discussion of what constitutes survivor research in Canada, this paper presents the findings of a critical discourse analysis of published accounts of survivor-led research over the last twenty-five years. Though they are varied, these texts demonstrate a rhetorical shift from a focus on the individual mind/body out to the social world experienced by psychiatric consumer/survivors. Findings indicate that survivor-led research engages with recovery discourse in numerous, sometimes problematic ways, in order to push back against dominant biomedical and psychiatric discourses. Further, new language is being generated for understanding madness and distress, rooted in a survivor perspective.
\end{abstract}

KEYWORDS: survivor research; user-led research; critical discourse analysis; Mad Studies

\section{Introduction}

This inquiry began with a question: what constitutes survivor research, and what does it look like in Canada? More specifically, I wondered: what's different about research produced by people who have experienced the mental health system? The simplest answer would seem to be the authors, the people who produce this research, are the difference. People who have experienced the mental health system have historically been excluded from traditional forms of knowledge production and are much less likely to receive or complete the expected academic training and credentials necessary to conduct and publish research studies. What Beresford refers to as our "hidden user knowledges" (2000a, 493) are socially devalued and have largely remained outside of conventional academic debates, canons and curriculum. So, to some extent it's true. But in another sense it isn't.

Identifying projects as survivor research requires more than a surface read of a text and cannot be determined simply by considering the identity of the author. Critical discourse 
analysis is used to show how survivor research rhetorically turns the readers' gaze out to the social and political conditions impacting psychiatric consumer/survivors' lives. This rhetorical turn centralizes consumer/survivor perspectives, in contrast to traditional mental health research where the focus is largely turned inward, towards to the individual mind/body. An analysis of twenty published accounts of survivor research shows how this field represents its work as a set of alternative politics and principles for conducting and disseminating research in a way that is inclusive of, and led by, consumer/survivors.

In this way, we can come to know about the kind of research Canadian consumer/survivors have led over the last twenty-five years through the texts themselves. Pursuing a study of this nature was significant in that there has never been a comprehensive review of Canadian survivor research published to date1. Critical discourse analysis, drawn from the work of Ian Parker (1990, [1992] 2004, 2004) is used to argue that any analysis of survivor research must come from a critical perspective; this is necessary in order to take into account political concerns about the effects of dominant discourse, and to capture survivor research's potential for creating methods of resistance.

The findings of this analysis are split into two sections, namely the politics and principles of research production. The section on politics asks how this corpus questions what counts as evidence and produces a process for conducting research. The section on principles asks: what are the underlying ideas guiding survivor research and how is it working towards building its own epistemology? This section ends with a reflection on how the rhetorical shift in perspective produced by survivor research has the potential to 'turn the tables' (Taylor, Abbott and Hardy 2012) towards a new language of madness and distress, provided some necessary conditions are met.

\section{Literature Review}

Survivor research goes by a few different names, including: survivor-controlled, survivor-led, user-led, user-controlled, or peer research, where 'survivor', 'user' or 'peer' refers to people who have past or present experience of the mental health system (Faulkner 2004). This paper adopts the term survivor research following the language of foundational publications in the field (Faulkner 2004; Sweeney, Beresford, Faulkner, Nettle, \& Rose 2009) and how it has been most recently cited (Russo \& Beresford 2015; Sweeney 2016). The terms used to describe this form of research depend on the politics of the research team as well as the geographic and institutional location of a project. Survivor research emerged out of and has remained closely linked to the psychiatric consumer/survivor/ex-patient movement, or mad movement, as it is more commonly referred to in Canada. The many terms used to describe survivor research reflect the various identity politics at play within the movement itself and the ways people choose to self-identify.

As this special issue reflects back on the last three decades of disability scholarship, it is important to note that survivor involvement in research has been documented in Canada

1 Under 'Case Selection' I describe the process by which I conducted a review of the literature that led me to recognize this gap. This was further confirmed by Dr. Kathryn Church, an authority in user involvement 
in Canada (personal communication). Additionally, a new project entitled the 'User/Survivor Research Networks in Canada: Feasibility Study' has recently noted that survivor research in Canada "is yet to be comprehensively explored." (See: http://www.socialinequities.ca/research/mental-health-reform/projects/)

since the 1980s (Church and Reville 1989) and survivor-led projects have been documented in Canada since the 1990s (for example: Users Designing the Future 1991). Though survivor research has been around for only a little over twenty-five years, it has grown significantly in that time (Rose and Beresford 2009; Sweeney 2013), particularly in the UK since 2000.

However, the vast majority of mental health and social service research in Canada does not involve service users beyond the role of research subject. The level of involvement can also vary significantly from one project to the next; the most common form of involvement typically entails consumer/survivors being asked to participate on a project in some capacity, but non-survivor professionals set out the terms of the research and make key decisions in advance of their participation. It distinguishes itself from other less involved forms of research and has been described as being on the highest level of a continuum of participation (Coney 2004; Dawson \& Voronka 2012). The definition of survivor research used within this paper incorporates both survivor-led and survivor-controlled projects. Though some differences can be noted between these two forms2, these terms are often used synonymously (Turner and Beresford 2005). My interest is in distinguishing between research led by consumer/survivors and less involved forms of consumer/survivor participation.

Among the rich and varied schools of thought informing survivor research, clear links can be made to emancipatory disability research. As noted by Barnes (2003), Oliver's (1992) article "Changing the social relations of research production" represented a major milestone; this particular work called for the advancement of an emancipatory paradigm for disability research. Like Barnes (2003) and Beresford (2009), Oliver (1992) drew from the work of feminists and black theorists and credits these epistemologies with the emergence of critical forms of inquiry and action research, which contributed to the development emancipatory disability research.

Following the disabled people's movement mantras "nothing about us without us" and "no participation without representation", emancipatory disability research aims to address the discrimination and oppression faced by disabled people by actively engaging them in the research process. Oliver (1992) argued that if disabled people are positioned to guide the research, it has the potential to shift the relations of research production and subsequently, create real material change to improve the lives of disabled people. Sweeney (2009) has described how survivor research was influenced by emancipatory disability research, particularly how it challenged traditional positivist research for medicalizing disability and how it criticized early forms of participatory research for 
research, it is not expected that all roles on the research team must be filled by consumer/survivors. Rather, all researcher partners (survivors or not) remain self-reflexive and committed to making their skills and resources available to a project that takes up a psychiatric survivor analysis.

failing to confront existing power structures. It's also important to note that the disabled people's movement and the mad movement have had distinctly different relationships to research from their respective outsets. Beresford (2009) has emphasized that "disabled people's engagement in research can be seen as one of the founding activities of the movement" (186), whereas survivor research has been an outcome of its movement activities, rather than central to its development.

To date there have been a great many more survivor research projects conducted in the UK than in Canada and the largest body of literature comes from the UK. Given that Canadian research in this field has been greatly influenced by that literature, and notable parallels exist between the UK and Canadian mad movements, this study focused on Canadian survivor research projects, but supplements them with a small number of UK-based studies. While UK-based studies are included, the intent is not to make international comparisons; rather, including both expands the pool of data and considers the context from which Canadian studies have emerged. In total twenty documents were selected for analysis; of these fourteen reported on survivor research projects from Canada and six reported on projects from the UK.

\section{Methodology}

Critical discourse analysis (CDA) was used to understand how survivor research's politics and principles are rhetorically represented within these twenty selected texts. This process, guided by Ian Parker's (1990) 'steps' for an analysis of discourse dynamics, involves posing a series of questions aimed at attending to consistencies across projects in terms of how subjects are positioned (including the reader), what objects are present or absent, and which rhetorical devises are used and how. These elements all provide clues as to how particular discourses are at work within each text. Taking a critical perspective, we must also consider how power relations shape discourse; in particular, how survivor research challenges the ways mainstream mental health discourses operate and this field's potential to create methods for resistance.

In order to appreciate survivor research's potential for creating methods of resistance, any analysis of survivor research, I would argue, ought to take a critical perspective. It is only through a critical analysis that we are able to take survivor research's political concerns about the effects of discourse into account. For instance, how subjects are repositioned through a process of self-identification that 'talks back to psychiatry' (Morrison 2005). Or, how survivor research takes seriously "hidden user knowledges" (Beresford 2000a, 493) both by challenging traditional research practices that act to systematically disqualify these forms of knowledge, and by refuting its intentions by making visible how psychiatric discourses uphold sanist ideologies.

As China Mills has pointed out, frameworks such as critical psychology "enact a different reading of mental health problems as distress, not illness" $(2011,60)$. While not all survivors may comfortable with critical psychology as an approach to take to this 
literature, I would argue that critical psychology is well-suited for this inquiry, because it is keenly aware of how psychology itself operates as a prominent discourse with increasing power the more firmly it becomes institutionalized (Parker 1990). Some critical psychologists, including Parker, have allied themselves with the psychiatric consumer/survivor/ex-patient movement, for instance, as part of the editorial collective of Asylum magazine, a long-time survivor publication from the UK. According to Parker (1990, 201):

"Discourse analysis should become a variety of action research, in which the internal system of any discourse and its relation to others is challenged. It alters, and so permits different spaces for manoeuvre and resistance."

\section{Case selection, or "How to spot survivor research"}

Identifying what counts as survivor research is a surprisingly challenging task. In some cases, researchers clearly identified their work as such, but more often the work is conducted in similar ways, but isn't explicitly identified as survivor research. This was the case in many of the Canadian studies, where the research methods were identified as community-based (CBR) or a form of participatory action research (PAR) with consumer/survivors as the community in question. The UK-based studies were easier to identify, since this field has been further established.

Survivor research appears in a number of genres (i.e. articles, reports, books) and some of these publications can be harder to locate than others, particularly when survivor research is produced as part of the 'grey literature'3 (Russo, 2012; Wykes, 2003). Identifying survivor research publications in Canada required a careful pulling together and sorting through a wide variety of documents. Altogether, a number of factors contribute to the difficulty in locating and distinguishing survivor research projects from other forms of research, namely: the diversity of identifiers used by consumer/survivors, the various terms used to describe survivor research in different contexts, the varying amount of control survivors have in any given project, the lack of established guidelines or parameters to follow (particularly in Canada), or a conventional literature base to reference, and lastly, a growing impetus within the field of qualitative mental health research to involve service users, in some capacity. Additionally, early publications can be especially hard to find, as documents may have only had a small initial circulation, may not have been well preserved, and may not be accessible online. This is an important element to keep in mind when we consider the potential influence and reach of this field.

Only published accounts of original research available in English were included in this analysis, and despite the possibility of expanding the pool of Canadian documents, published accounts of individual student research projects were excluded. Only projects that were either led or fully controlled by consumer/survivors were included for analysis. Determining what constitutes survivor research requires a careful read of documents, to gauge the levels of participation and power sharing on a project. This is noted in order to illustrate the difficulty in making determinations about whether or not to exclude certain publications and to highlight the complicated nature of identifying Canadian survivor research in text. It was at times unclear from the initial scan whether 'participatory' 
3 Grey literature generally refers to documents produced by sources (academic, government, community based, etc.) whose main task is not commercial publishing. Grey literature has not been peer-reviewed prior to publication.

processes were more of a consultation, or if they truly involved and were led by consumer/survivors.

Only published accounts of original research available in English were included in this analysis, and despite the possibility of expanding the pool of Canadian documents, published accounts of individual student research projects were excluded. Only projects that were either led or fully controlled by consumer/survivors were included for analysis. Determining what constitutes survivor research requires a careful read of documents, to gauge the levels of participation and power sharing on a project. This is noted in order to illustrate the difficulty in making determinations about whether or not to exclude certain publications and to highlight the complicated nature of identifying Canadian survivor research in text. It was at times unclear from the initial scan whether 'participatory' processes were more of a consultation, or if they truly involved and were led by consumer/survivors.

Below I provide one example of a scenario where a determination was made about whether or not to exclude certain publications. I share this in order to illustrate the complicated nature of identifying Canadian survivor research in text. Untangling survivor research from other forms of user involvement proved to be the most difficult part of the case selection process. I would argue that in future, Canada survivor research could benefit from differentiating their work, as it will help to identify the literature and establish the field. As I read through the documents, I asked: did consumer/survivors have any control over decision-making? Was there power sharing on the research team, or even recognition of existing power imbalances? I searched for clues and tracked my decision making process throughout.

One joint Canadian and American study claimed to be user-led in its title, and "as 'userled' as possible" within the body of the text (Pelletier et al. 2011, 4), but it was excluded based on a number of factors. First, all seven authors listed on the article are academics, none of whom self-identify as consumer/survivors. The language in the article is highly academic, includes numerous research acronyms (i.e. IKT = Integrated Knowledge Translation), and is not at all aimed at or for mental health service users. The document uncritically adopts the aims of the Movement for Global Mental Health (MGMH) despite vocal criticism of this model from allies of the mad movement (Mills 2014; Mills and Fernando 2014). Looking at the project's timeline, it becomes clear that services users became involved only in the final stages of a knowledge translation project. Two psychiatric institutions in Montreal provided the financial support for the project. Nowhere in the text is there any acknowledgement of any work or scholarship produced by Canadian or American consumer/survivors; the reference list includes only two UK Page based survivor research publications. The following quote further illustrates why this project, though claiming to be user-led, was excluded from consideration. It states:

"This report is thus part of an End of Grant KT plan that emanates from an IKT 
initiative where researchers, decision/policy makers, and mental health service users were somehow becoming peers to each other, as described below"

[emphasis added] (Pelletier et al. 2011, 5).

The term 'peers' within Canadian mental health literature generally refers to people who have experienced the psychiatric system, from the inside (i.e. peer research $=$ survivor research). Here the authors recycle the word 'peers' in a way that makes invisible existing power imbalances between these three 'stakeholder' groups on the project. The use of the word 'somehow' suggests a lack of conscious effort to rectify these power imbalances through the process (i.e. It happened, somehow).

\section{The politics of research production: Questioning what counts as evidence}

Within this corpus, a number of survivor research publications brought up questions of what counts as evidence. Though not all texts spoke in terms of generating evidence, those that did recognized evidence as an important component of research and necessary for effective service delivery. Some studies spoke of generating evidence through their findings to challenge professionals' assumptions, or spoke of the need to generate evidence in order to make an economic case for greater resourcing (OCAB 2009; Taylor, Abbott and Hardy 2012). Past survivor-led studies were referenced to provide evidence to support choices around survivor research practices, such as having peers conduct interviews (Habitat and OCAB 2010) or to challenge prevalent psychiatric practices, such as the overreliance on drug treatments (Morrow with Chappell 1999).

Newberry and Strong (2009) expressed hope that their study, which aimed to develop an evaluation framework for mental health services based on recovery-focused outcomes, could serve as an example of evidence-based practice. They identify a need to develop new outcome measures that are accountable to the goals of recovery as an increasing number of services become 'recovery-oriented'. O'Hagan et al (2010) identify a pressure on peer-led initiatives to engage with mainstream research methods and evaluation processes as necessary for them to remain relevant in an 'evidence-based' system. They suggest peer-led organizations begin with a dialogical process, "asking key questions about the meanings for them of knowledge, evidence and how the evidence-based practice approach will impact peer support services" $(2010,29)$. Further, O'Hagan et al. (2010) emphasize the importance of survivor-led research for producing a philosophy for research that values survivors' experiences and figures out ways of incorporating those experiences into outcome measures and evaluation processes.

"Creating methods and approaches to better understand peer support in ways that are consistent with the values of the consumer/survivor movement is a key area for future research." (O’Hagan et al. 2010, 29)

A recurring metaphor of 'the textbook' is used within Voronka et al.'s (2014) study to highlight a disconnect between the mental health and social service providers participants identified as helpful, and those they identified as offering unhelpful help. Service providers who were willing to "throw out the textbook" (257) (i.e. those who were compassionate, or empathetic) were found to be more helpful, whereas professionals who 
worked by, or stuck to "the textbook" (257) (i.e. those who had become desensitized, or were 'just doing a job') were identified as unhelpful. This metaphor was drawn from multiple participant quotes and was reiterated in the texts' sub-headers.

This example shows how participants' knowledge was used to guide how help was conceptualized within the study. The importance of 'book learning' is disputed, as "help that comes out of life experience or that comes from the heart" (Voronka et al. 2014, 261) is found to be more valuable. In this way, the study rhetorically challenges the conventional forms of knowledge valued by professionals (i.e. the 'textbooks') as unsuitable for addressing service users' needs.

One UK-based study contested how Crisis Response and Home Treatment (CRHT) services had been evaluated by randomized control trials (or RCTs), but noted that RCTs are "regarded as 'gold standard' in the hierarchy of clinical trials evidence" (Middleton et al. 2011, 148). Middleton et al. (2011) argue that clinical trials are inappropriate to evaluate crisis treatment's effectiveness and that qualitative, interpretive methods are better suited to the task. They point to how clinical trials are limited in that they cannot take inter-subjective relational elements into account, even where these affect outcomes. What's more, RCTs do not take into account the costs to individuals of the impact of a treatment. Even in ideal conditions, Middleton et al. (2011) assert that RCT requirements could not be adequately met; it would be impossible to hold all of the experiment variables constant or keep research participants and administering practitioners in the dark as to whether or not participants are receiving (crisis response) treatment. This text challenges a dominant discourse of evaluation by contending that the positivist, objective measurements this discourse promotes are not suitable for particular kinds of crisis interventions. In this way, this text expresses a resistance to objectifying participants' experiences of crisis treatment as both ineffective and inappropriate.

The survivor research texts I examined are engaged in practices of evaluation and as such, generate evidence and knowledge. However, they contend with the ways in which a dominant discourse of evaluation reproduces existing power relations that disadvantage consumer/survivors. This discourse of evaluation insists on the application of certain research methods and standards (such as randomized control trials, or others high up on the 'hierarchy of evidence'), which generate conventional forms of knowledge ('the textbook') that do not meet the needs of consumer/survivors or reflect the values of the mad movement. Instead, these texts proposed alternative methods for generating evidence that they claim more effectively capture "what counts" to consumer/survivors. In this way, this corpus critiques and questions the prominence of evidence-based medicine, and grapples with its own engagement with these practices. Through the application of survivor research methods, these texts rhetorically produce an alternative object of evaluation; one, which they contend, better reflects the needs of consumer survivors and the values of the movement.

\section{The politics of research production: The relational element}

Many of the studies reported findings that emphasized the relational elements of support and service provision, such as empathy, listening and being treated with respect, as 
tantamount. This relational element appeared over and over across the texts, even as the object of study varied significantly. Russo and Rose (2013) state:"The majority of participants saw personal relations with staff in psychiatric institutions as a high priority area when thinking about human rights." (Russo and Rose 2013, 189). Likewise, Coltman et al.'s (2015) study of community integration urged helping professionals " $t o$ respect the importance of the development of relationships in the process of community integration" (Coltman 2015, 49).

Middleton et al. (2011) emphasize how what survivors value can be hard to measure with quantitative tools: "Relationship cannot be measured and identified as a variable contributing to part of an empirical experiment" (153). This resonates with what McKeown et al. (2010) sum up nicely as: "what counts cannot be counted". However, studies such as Rose's (2003) user-led survey of the Care Program Approach (CPA) effectively demonstrate how quantitative methods could also be adapted to become user-focused. In their final discussion section, Taylor, Abbott and Hardy (2012) cite numerous studies that share similar findings to theirs, of the importance of affective communication and continuity of relationships between service users and professionals. They express frustration with the fact that "these requirements have been articulated for many years, and their continuing articulation suggests that services remain largely unresponsive." (Taylor, Abbott and Hardy 2012, 453)4. Church, as part of Mental Health "Recovery" Study Working Group (2009), expresses similar frustration with recurring findings: "Almost twenty-five years later, the participants in our study pinpointed precisely these same issues" (29). These expressions of frustration highlight how survivor research has a political stake in shifting the evidence 'measuring stick'. Faulkner and Nicholls (2003) pose this question:

"How, then, can we best challenge conventional notions of evidence in order to place the service user (and user-defined strategies and outcomes) at the centre of mental health care?" (2).

Survivor research texts discursively produce value in a different way in order to challenge established methods of evaluation, and so that what concerns survivors (here: the relational element) can carry weight and subsequently, leads to changes in practice. These texts do so by consistently drawing from and valuing the firsthand accounts and meaning survivors' make of their own experiences. In order to put an end to these 'recurring findings', survivor research must use the knowledge it generates to make visible how conventional research practices are discursively reproducing destructive experiences for survivors.

\section{The politics of research production: Questioning the research process}

In conjunction with questioning what counts as evidence, survivor research has a political stake in questioning conventional research processes. This corpus produced a process for conducting survivor research by stressing specific aspects that it deems valuable. First, following from its discursive connection to community-based research, participation by survivors throughout the research process is emphasized. Second, survivors are 
4 Survivors contributing to the INFORM study volunteered their time for six years, indicating a strong commitment to the project (Taylor Abbott and Hardy 2012).

foregrounded in survivor research as capable, active agents and their subject locations are universally recognized within these texts as an asset to the research process. Third, this corpus emphasized the need for the process to lead to social change, particularly change that will improve consumer/survivors lives. Lastly, it critiqued processes of "consumer participation" (less involved forms of user involvement), to highlight user involvement's limitations and to reinforce support for a distinct survivor research process.

Survivor participation throughout the research process was emphasized in a number of ways. A few of the texts narrated how for some consumer/survivors, past experiences of psychiatric, pharmacological or other forms of research may have been oppressive; these past experiences of being researched on, in the interest of others, impact survivors' individual and collective future interactions with research. These texts also emphasized the importance of taking steps to equalize power relations between the people being researched and the researchers. Doing so can build trust amongst potential participants. Voronka et al. (2014) noted how peer research must be held accountable to the community being studied.

Numerous studies expressed the value of the interviewer and interviewees sharing the past experience of madness and distress in common. This was considered advantageous in that it afforded the research team access to this community, and improved the richness of the data when interviewees feel comfortable enough to open up and share. Faulkner \& Nicholls (2003) note one benefit of having a service user conduct the interview is that the interviewer may not be perceived as having the power to alter or revoke any services the participant might want to criticize, but relies upon and can't risk putting in jeopardy. It should be noted, that while the idea of using community members as interviewers within community-based research is nothing new, because of the particular forms of paternalism and discrimination survivors face which position them as irrational and dangerous, survivor researchers encounter additional barriers. For instance, one project reported on being met with "disinterest and even hostility" by service workers for having service users interview other service users (Rose 2003, 63).

Reflecting an emancipatory paradigm, survivor participants are frequently positioned within these texts as knowledgeable, active agents, capable of speaking on their own behalf. Looking at the use of verbs in Reid and Poole (2013)'s text shows how mad student study participants are positioned as active and capable:

"All participants called for the creation of at least one core course on AOP in mental health." (217)

"Far from being needy, these student participants were talking concretely about what the university can do with them as opposed to for them." (219)

"The message was clear that the students were looking to develop ways in which they can help each other - to have their needs as mad people be met by peers and not just by professionals."(219) 
The Mental Health "Recovery" Study Working Group (2009) used participant quotes and the rhetorical organization of their findings to affirm survivors as knowledgeable and able to critique a range of powerful institutions, as well as the emerging professionalization of 'recovery' discourse in community mental health. These rhetorical strategies indicate that survivor research is rooted in a premise whereby the meanings consumer/survivors give to their own experiences, not only of madness and distress, but also the systems and structures they encounter through those experiences, are valued and respected. Correspondingly, some studies remarked on their participants' insider knowledge of supportive housing and peer support.

Some texts stressed the importance that the research process must lead to change, that it isn't enough for survivor research to just gather evidence and publish the results; the end goal of the process is to produce outcomes that improve the lives of consumer/survivors (for instance, OCAB 2009; Taylor, Abbott and Hardy 2012). Because research topics were survivor generated, it could be expected that study findings would be of interest to consumer/survivors. Still, it would be limiting to consider survivor research as benefitting only consumer/survivors; by challenging dominant psychiatric discourses and proposing an alternative discourse of madness and distress, as we will see, survivor research can also benefit other 'stakeholders'. Developing new forms of knowledge about how to improve consumer/survivors lives also serves to improve the service systems they encounter (Turner and Beresford 2005).

The rhetorical gesture towards social change as an outcome of survivor research's process included calls for a paradigm shift. Morrow with Chappell (1999) "advocate a paradigm shift that acknowledges the inadequacy of bio-medical explanations for understanding women's mental health." (4). Likewise, Russo and Rose (2013) call for a paradigm shift in approaches to madness and distress, because, they argue:

"...if all of these choices stay lodged within the biomedical approach to human crisis, then we may continue to neglect the most important avenues for personal growth and living to one's full potential. Work towards these possibilities cannot take place within any framework which focuses exclusively on improving what is already in place" (191).

Along a similar vein, the first in a list of recommendations made by Habitat and OCAB (2009) states that a "radical attitudinal shift must take place in social service agencies at all levels of the organizations..." (4). While not unconventional in the genre of community report, this corpus also produces an imperative of social change by listing 'recommendations' that identify actions to be taken up by identified stakeholder groups5. These recommendations frequently challenged dominant biomedical discursive practices, aimed to strengthen recovery-oriented approaches, or sought to establish and support alternative approaches to madness and distress.

A further way that the research process is produced as an object of reflection in this corpus is through accounts that critique processes of user involvement (for example: 
5 See, for instance: Faulkner and Layzell 2000; Habitat and OCAB 2009; Morrow and Chappell 1999;O'Hagan et al. 2010; OCAB 2009.

Church 1996 and Rose 2003). These accounts critique user involved projects for moving ahead even when the ethical implications of consumer participation hadn't been fully thought through by those involved, particularly with survivor concerns in mind. Professionals, academics and clinicians usually govern research ethics boards (REBs). The Mental Health "Recovery" Study Working Group (2009) discussed their ethics review process at great length, something not often done in academic reports beyond a short acknowledgement of completion, to draw attention to the difficulties they encountered stemming from their decision to hire consumer researchers, since consumers fit the category of 'vulnerable populations'.

\section{The principles of research production: Resisting psychiatry}

Analysing the discourses within these texts permits us to learn about the principles underlying survivor research. Though they are varied, these texts represent a collective effort to develop survivor knowledge and reclaim the meaning of madness and distress. Although the language of madness, and the emergent field of Mad Studies, is associated with the most recent wave of the Canadian mad movement, this language appeared only in some of the more recent publications. But taking a close look at how survivor research texts resist psychiatric discourse, and struggle with the professionalization of an emerging recovery discourse, gives us a glimpse into how spaces are being created to generate alternative ways of understanding madness and distress rooted in a consumer/survivor perspective.

To varying degrees, each of these texts included challenges to psychiatric and medical discourses that frame madness and distress according to the language of 'mental illness'. Reid and Poole (2013) reject medical discourse outright, stating: "we set our inquiry apart from a traditional, pathologizing orientation to 'mental health and illness", (210). The ways in which they reassured participants that supports were available, should they need them, also indicated a non-medical orientation. A number of studies made mention of rights violations and forms of violence inflicted by the psychiatric system6. In a subtler way, Newberry and Strong (2009) refer to medicalized and professionalized outcome types (the first of four in a progression) as the more 'traditional' approaches, that are "somewhat narrow" (74) and that on their own, they "fail to capture a fuller and more holistic picture of mental health" (75).

In the study 'Hearing Women's Voices', Morrow and Chappell (1999) challenge psychiatric discourse on a number of fronts. In order to date and dismiss it, they call out ways in which psychiatric discourse has served patriarchy. Psychiatric diagnoses are proposed as the problem, not the solution, and have served as a justification to deny healthcare. Additionally, they challenge psychiatric discourse by linking it to a history of colonialism:

"In Canada, there has been a systematic erasure of Aboriginal healing practices and there is much evidence to show that people of colour and immigrant peoples 
6 For instance: Mental Health "Recovery" Study Working Group 2009; Morrow with Chappell 1999; Russo and Rose 2013; Shimrat 2002.

have historically been pathologized and controlled through the practice of psychiatry" (Morrow and Chappell 1999, 45)

Moreover, they draw from the work of other critical academics to build an argument for how medical and psychiatric discourses have provided the rationale that legitimized colonial practices, which ultimately serve dominant western political and economic purposes.

Other texts employed rhetorical devices to demonstrate their resistance. Voronka et al. (2014) use participant quotes throughout to illustrate their critique; they describe containment in "rubber rooms" (263), speak of the "weight of medication" (262), how it can box you in and make you feel like a zombie" (264), and depict experiences of the hospital as "routinized and monotonous" (263). Likewise, Shimrat (2002) plays with the double meaning of the word swallow in stating: "we are taught to swallow, unquestioningly, daily doses of various psychiatric drugs" (4), implying both the pills and the ideas they are premised on.

\section{The principles of research production: 'Talking recovery'}

Recovery discourse was prominent throughout, but was taken up in various differing and sometimes conflicting ways. Recovery-oriented approaches were often referred to as 'alternatives' and 'a more holistic approach' than 'dominant' or 'mainstream' biomedical approaches. Voronka et al. (2014) refers to recovery as connected to an "emerging structure", implying that this discourse is becoming increasingly institutionalized in Canada. This text indicates support for recovery-oriented approaches, which it sees as more collaborative, self-directed, focused on 'well being', and linked to a social model of care.

A small number of these studies uncritically adopt a recovery discourse. For instance, Newberry and Strong (2009) propose to develop a new evaluation framework to measure recovery-oriented focused outcomes; however, they never question why mental health services have chosen to adopt recovery principles without connecting them to outcome measures. It's also striking that Newberry and Strong (2009) fail to consider recovery's multiple, sometime ambiguous meanings, especially when another survivor-led project from Ontario written in the same year took up participants' understandings of recovery along three lines: as a personal journey, as a social process, and as a critique of a range of institutions, including psychiatry, healthcare, pharmaceuticals and the police (Mental Health “Recovery” Study Working Group's 2009).

Recovery discourse is only mildly challenged by de Wolff et al. (2009). Apart from one instance, where recovery is said "to have a more individual, psychological language" (63) the remainder of the article focuses on the similarities between recovery, empowerment and participatory research. The title and sub-headers of the article affirm a recovery discourse (for instance "Meaning, Purpose and Challenging Stigma", "Hopeful 
Findings", etc.). In fact the article recounts the project as a kind of collective recovery narrative. This is further affirmed by the fact that the actual findings of the study are not presented within the article, only briefly summarized. The text positions participatory research as contributing to the recovery of the survivors on the project; it fails to acknowledge how the exercise in and of itself isn't enough if the aims of the research aren't met (in this case, if NIMBY ism isn't addressed, or new supportive housing units aren't built). Perpetrators of discriminatory practises and policies are not called out; instead this feel-good narrative serves to make its intended audience of community based researchers and practitioners feel good about the work they do.

Pitt et al. (2007) start by introducing the 'concept' of recovery historically; however, this history begins from the biomedical model and fails to consider anything that might have come before. Introducing recovery chronologically serves to suggest a progression away from the biomedical model, but starting from the biomedical erases the history of previous approaches to madness, and boundaries the conversation to these two possible approaches. Drawing from the study's findings, we see how recovery is referred to as a "relative concept" and "a gradual and uneven process, occurring in stages involving turning points and milestones, without definitive end" (Pitt et al. 2007, 57); this definition reproduces the common metaphor of recovery as a journey or path, which individualizes the experiences of madness.

A building metaphor is used in the thematic grouping of Pitt et al.'s (2007) three findings: 'Rebuilding the self', 'Rebuilding life' and 'Hope for a better future'. While the first two forms of 'rebuilding' might suggest a split between individual and social elements to recovery, a closer look at the bullet points in each of these three themes reveals they are both heavily focused on the individual; even social elements are presented as work for the individual to achieve, such as: "developing family support", "developing social relationships and networks" and "challenging people's beliefs" (Table 1, 57). Under the sub-theme 'Empowerment' findings are equally focused on the work of the individual: "seeking knowledge", "taking control", "self-motivation", "self-reliance", "self-esteem", "self-assertion", "self-recognition", etc. (Table 1, 57). How the concept 'empowerment' is taken up in this text differs greatly from how it is taken up by survivors elsewhere, such as when it can have an explicit focus on power, politics, rights and community integration.

What's more, the study fails without a critical analysis or the reflexivity necessary to question its use of recovery as a framing device. For example: a point is made about the "importance of voluntary work in creating a sense of purpose in life" (58); this point is supported by a participant quote, which states:

"I spend most of my time working for the network... I go out and do training and we kick start the Hearing Voices groups in various towns and that sometimes you have a group to talk to a group of CPNs [community psychiatric nurses] or social workers." Pitt et al. 2007, 58).

This quote is framed within the text as evidence to support the idea that volunteer work is a beneficial component of an individual's recovery; it fails to mention how survivors' 
volunteer work benefits the mental health system, provides unpaid training for mental health professionals, or creates alternative supports for other survivors. The quote is framed to direct the reader to interpret the value of this work as 'good for' the person in recovery. So while texts such as these indicate openness to critiquing the mental health system (specifically biomedical approaches) they uncritically adopt a recovery discourse.

Though the consumer/survivor movement is noted as being one of the originating sources of recovery discourse, some of these survivor research texts questioned the ways in which recovery is being taken up, with an eye to the political motivations for implementing these approaches (O'Hagan et al. 2010). Some studies criticized how recovery is being co-opted and professionalized, particularly when recovery is tied to neoliberal discourses that justify austerity measures and cost-cutting, or when it is solely located within the individual (as the 'personal journey' of recovery), and collective issues such as survivors' rights and systemic advocacy go missing.

"What is most interesting and paradoxical about the growth of the "recovery" movement in and outside of hospitals, is that it coincides with the implementation of community treatment order (CTO) legislation (2000) and with an increase in the number of people being pushed through the mental health and criminal justice systems. It is another example of the system shrewdly appropriating psychiatric survivor knowledge without giving up any of its power. The magnetism of recovery talk, the "hope talk" is picked up while the contentious bits regarding citizenship and advocacy are left behind." (Lucy Costa, in Mental Health "Recovery" Users and Refusers 2009, 35).

\section{The principles of research production: Reclaiming madness}

Despite the prominence of recovery within these texts, there are indications that survivor research is creating new language for understanding madness and distress. The clear lack of consistent language across the texts in particular is a reflection of how survivor research, following the principles of the mad movement, respects people's right to self-identify. Even where survivor researchers embrace the language of madness, such as with Reid and Poole (2013), various terms are still used as they try to remain flexible to participants' own ways of describing their experiences.

Hints of an emerging discourse can be found in the alternative 'objects' that appear, such as: distress, crisis, altered states, the experience of 'hearing voices', and the 'Hearing Voices' network of support groups, 'voice' (when referring to a collective consumer/survivor voice), "the needs of mad students" (Reid and Poole 2013, 217), "mad-friendly responses" (Reid and Poole 2013, 214), and even "how to access decent supports" (Reid and Poole 2013, 218). Additionally, signs become evident through the use of rhetorical devices. Voronka et al. (2014) cheekily include a sub-header that riffs off the survivor mantra 'A home, a friend, and a job' by declaring "A Home, Money and A Job", highlighting participants' expression of money as an essential need. The terms 'psychiatrized' and 'medicalized' emphasize the oppressing force of other discourses (Morrow and Chappell 1999; Shimrat 2002), and the language of 'sanism' and 
'mentalism' (Reid and Poole 2013) underscore the ideological force of language that 'others' mad experiences.

At times, these texts also took anti-psychiatry positions, or delimited and differentiated themselves from those positions, while still advancing their critiques (Shimrat 2002; Morrow and Chappell 1999). For instance, Morrow and Chappell state:

"Anti-psychiatry activists, on the other hand, draw attention to the predominance of the biomedical paradigm and the ways in which the practice of psychiatry is interdependent with the pharmaceutical industry." (25)

\section{Conclusion}

Canadian survivor research to date has focused on a wide range of topics such as: barriers to employment, the emergence of peer support, safe houses for women, the neighbourhood impact of supportive housing, among others. These turn the reader's attention out to the world experienced by consumer/survivors. This shift in perspective is not premised on the notion that the internal states of individuals struggling with mental health issues must be known in order to understand their behaviour. Rather, through this positioning, the reader's gaze comes to attribute madness and distress to the social conditions of poverty, oppression, systemic violence, trauma and a lack of adequate, accessible supports and resources. Taylor, Abbott and Hardy (2012) refer to this as 'turning the tables', to attend to the experiences of survivors, instead of the clinical problematics that dominate mainstream mental health research. In 'turning the tables', Canadian survivor research that is critical and rigorous in its practice, has the potential to develop new ways of understanding madness and distress rooted in a consumer/survivor perspective.

By questioning what counts as evidence Canadian survivor research challenges conventional forms of knowledge production. It contends with a discourse of evaluation that reproduces existing power relations that disadvantage consumer/survivors and proposes an alternative application of survivor research methods to generate evidence that more effectively captures "what counts" to consumer/survivors. This corpus produced a process for conducting survivor research by emphasizing the participation of survivors throughout the research process, by foregrounding survivors and positioning them as capable, active agents, and by emphasizing the need for research to lead to social change. Further to this, these texts critiqued processes of 'consumer participation', those lesser involved, tokenistic forms of user involvement.

These texts engaged with a recovery discourse in order to push back on dominant biomedical and psychiatric discourses. They took up recovery in numerous ways, at times uncritically adopting it, mildly challenging it, or even applying it in contradictory or problematic ways. However, a few texts within in the corpus critiqued recovery, particularly the ways in which this discourse is being co-opted and professionalized. The form recovery takes when propped up by neoliberal or professional discourse is heavily focused on the individual's 'personal journey' of recovery, and becomes stripped of collective concerns, such as systemic advocacy and citizenship. I argue that survivor 
research must retain the sharp critique the mad movement has been known for, and bring this critique into the way it uses or resists recovery discourse going forward.

In order to learn from the past and build the future, archival work that knits together and critically examines previously published but sometimes hard to locate accounts of survivor research is necessary for building the Mad Studies canon. This follows from what was envisioned by Beresford and Wallcraft (1997) some twenty years ago:

"The growing body of emancipatory research being undertaken by survivors is beginning to point to a clearer philosophical basis for the movement. There is a growing recognition from within that the movement needs to develop its own philosophy” (84).

This paper argues that any analysis of survivor research must come from a critical perspective; this is necessary in order to take into account political concerns about the effects of dominant discourse, and to capture survivor research's potential for creating methods of resistance. Additionally, Canadian survivor researchers would be well served by differentiating their work from other forms of participatory or community-based methods going forward; doing so will make it easier to identify the literature and help establish the field so subsequent researchers need not 'reinvent the wheel'. Even though Disability Studies and Mad Studies are not always in sync, the inclusion of this article speaks to Disability Studies as an international, interdisciplinary and growing field that has embraced survivor research and Mad Studies (Spandler, Anderson and Sapey, 2015; Ingram 2016). As Beresford (2000b) aptly pointed out nearly two decades ago, despite significant differences, the relations between disabled people and consumer/survivors should not be overlooked.

\section{APPENDIX OF SELECTED PROJECTS}

\section{Canadian Projects (14)}

Church, Kathryn. 1996. “Beyond 'Bad Manners': The Power Relations of 'Consumer Participation' in Ontario's Community Mental Health System.” Canadian Journal of Community Mental Health, 15(12): 27-44.

Coltman, Linda, Susan Gapka, Dawnmarie Harriott, Michael Koo, Jenna Reid and Alex Zsager. 2015. "Understanding Community Integration in a Housing-First Approach: Toronto At Home/Chez Soi Community-Based Research." Intersectionalities: A Global Journal of Social Work Analysis, Research, Polity, and Practice, 4(2): 39-50.

deWolff, Alice in consultation with Pedro Cabezas, Linda Chamberlain, Aldo Cianfarani, Phillip Dufresne, Peter Lye, Dennis Morency, Bradley Mulder, Esther Mwange, and Mark Shapiro. 2009. "The Creation of 'We Are Neighbours': Participatory 
Research and Recovery." Canadian Journal of Community Mental Health, 28(2):

61-72.

Gumpp, Ruth for Consumers for Knowledge Exchange and Research (CONKER). 2009.

Hope and Fear: Consumers, Psychiatric Medications and the Therapeutic

Relationship. Vancouver, BC: CONKER Mental Illness. Retrieved from:

http://www.psyrehab.ca/files/documents/Hope\%20and\%20Fear-

\%20CONKER\%20Report\%20September\%202009.pdf

Habitat Services and the Ontario Coalition of Alternative Businesses. 2010, May. Breaking Ground: Peer Support for Congregate Living Settings. Toronto, ON:

Wellesley Institute. Retrieved from: http:/www.wellesleyinstitute.com/wpcontent/ uploads/2010/05/Breaking_Ground_final_final_report.pdf

Mental Health "Recovery" Study Working Group. 2009, January. Mental Health

"Recovery": Users and Refusers. Toronto, ON: Wellesley Institute. Retrieved from: http://www.wellesleyinstitute.com/wpcontent/

uploads/2011/11/Mental_Health-_Recovery.pdf

Morrow, Marina with Monika Chappell. 1999. Hearing Women's Voices: Mental Health Care for Women. Vancouver, BC: British Columbia Centre of Excellence for Women's Health. Retrieved from: http://bccewh.bc.ca/wpcontent/ uploads/2012/05/1999_Hearing-Womens-Voices.pdf

Newberry, D. Jason and Allan D. Strong. 2009. "Beyond Mental Health Maintenance: An Evaluation Framework Driven by Recovery-Focused Outcomes.” Canadian Journal of Community Mental Health, 28(2): 73-94.

O’Hagan, Mary, Celine Cyr, Heather McKee and Robyn Priest. 2010. Making the Case for Peer Support: Report to the Mental Health Peer Support Project Committee of the Mental Health Commission of Canada.

Ontario Council of Alternative Businesses. 2009. Not for Lack of Trying: Barriers to employment and the unrealized potential of psychiatric survivors living in boarding homes. Toronto, ON: Wellesley Institute.

Reid, Jenna and Jennifer Poole. 2013. "Mad Students in the Social Work Classroom? Notes From the Beginnings of an Inquiry." Journal of Progressive Human Services 24(3): 209-222.

Rodriguez del Barrio, Lourdes, Celine Cyr, Lisa Benisty and Pierrette Richard. 2013. "Autonomous Medication Management (GAM): New Perspectives on Wellbeing, Quality of Life and Psychiatric Medication." Ciência \& Saúde Coletiva, 18(10): 2879-2887

Shimrat, Irit. 2002, September. What Women Want: The Vancouver/Richmond Mental 
Health Network Society Safe House Project. Funded by Status of Women Canada, BC/Yukon Division.

Voronka, Jijian, Deborah Wise Harris, Jill Grant, Janina Komaroff, Dawn Boyle, and Arianna Kennedy. 2014. "Un/Helpful Help and Its Discontents: Peer Researchers Paying Attention to Street Life Narratives to Inform Social Work Policy and Practice." Social Work in Mental Health, 12(3): 249-279.

\section{UK Projects (6)}

Faulkner, Alison, and Sarah Layzell. 2000. Strategies for living: a summary report of user-led research into people's strategies for living with mental distress. London: Mental Health Foundation.

Middleton, Hugh, Rebecca Shaw, Ron Collier, Aimie Purser and Brian Ferguson. 2011. "The Dodo Bird Verdict and the Elephant in the Room: A Service User-Led Investigation of Crisis Resolution and Home Treatment." Health Sociology Review 20(2):147-156.

Pitt, Liz, Martina Kilbride, Sarah Nothard, Mary Welford, and Anthony P. Morrison. 2007. "Researching Recovery from Psychosis: A User-led Project." Psychiatric Bulletin 31(2): 55-60.

Rose, Diana. 2003a. "Partnership, Co-ordination of Care and the Place of User Involvement." Journal of Mental Health, 12(1): 59-70.

Russo, Jasna and Diana Rose. 2013. "'But What if Nobody's Going to Sit Down and Have a Real Conversation With You?" Service User/Survivor Perspectives on Human Rights. Journal of Public Mental Health, 12(4), 184-192.

Taylor, Sue, Stephen Abbott and Sally Hardy. 2012. "The INFORM project: A Service User-Led Research Endeavor.” Archives of Psychiatric Nursing, 26(6): 448-456.

\section{REFERENCES}

Barnes, Colin. 2003. "What a difference a decade makes: reflections on doing 'emancipatory' disability research.” Disability \& Society, 18(1): 3-17.

Beresford, Peter. 2000a. "Service Users' Knowledges and Social Work Theory: Conflict or Collaboration?" The British Journal of Social Work, 30(4): 489-503.

Beresford, Peter. 2000b. "What Have Madness and Psychiatric System Survivors Got to Do with Disability and Disability Studies?” Disability \& Society, 15(1): 167-172.

Beresford, Peter. 2009. "User-controlled research.” In Handbook of Service User Involvement in Mental Health Research, edited by J. Wallcraft, B. Schrank, and M. Amering. West Sussex, UK: Wiley-Blackwell. 181-198. 
Beresford, Peter and Wallcraft, Jan. 1997. "Psychiatric System Survivors and Emancipatory Research: Issues, Overlaps and Differences.” Pp. 66-87 in Doing disability research, edited by C. Barnes and G. Mercer. Leeds, UK: Disability Press.

Church, Kathryn and David Reville. 1989. "User Involvement in the Mental Health Field in Canada." Canada's Mental Health, 37(2): 22-25.

Church, Kathryn and David Reville. 1991, October. 'Users Designing the Future': Demystifying the Politics of Psychiatric Consumer/Survivor Participation. (Unpublished report). Developed for the Secretary of State of Canada Disabled Persons Participation Program.

Coney, Sandra. 2004. Effective Consumer Voice and Participation for New Zealand. New Zealand Guidelines Group.

Dawson, Sandra and Jijian Voronka. 2012. "Diversity in Peer Engagement in At Home/Chez Soi: Types of Research Involvement.” Poster presentation for Critical Inquiries in Mental Health Inequities: Exploring Methodologies for Social Justice. Centre for the Study of Gender, Social Inequities and Mental Health, Vancouver, BC. Retrieved from: http://www.socialinequities.ca/wordpress/wpcontent/ uploads/2012/06/Dawson-CI-2012-Poster.pdf

Faulkner, Alison. 2004. The Ethics of Survivor Research: Guidelines for the Ethical Conduct of Research Carried out by Mental Health Service Users and Survivors. Bristol, UK: Policy Press, on behalf of the Joseph Rowntree Foundation.

Faulkner, Alison and Vicky Nicholls. 2003. "User-led Research: Towards a Radically Different Mental Health System.” Retrieved from:

http://www.critpsynet.freeuk.com/Faulkner.htm

Ingram, Richard A. 2016. "Doing Mad Studies: Making (Non)sense Together." Intersectionalities, 5(3): 11-17.

LeFrancois, Brenda, Robert Menzies and Geoffrey Reaume, eds. 2013. Mad Matters: A Critical Reader in Canadian Mad Studies. Toronto, ON: Canadian Scholars' Press.

McKeown, Mick, Lisa Malihi-Shoja and Soo Downe. 2010. Service User and Carer Involvement in Education for Health and Social Care. West Sussex, UK: Blackwell Publishing.

Mills, China. 2011. "Live and let die: Global mental health and critical disability studies." In Distress or Disability? Proceedings of a symposium held at Lancaster University, 15-16 November 2011, edited by Jill Anderson, Bob Sapey and Helen Spandler, $57-61$. 
Mills, China. 2014. Decolonizing Global Mental Health: The Psychiatrization of the Majority World. London: Routledge.

Mills, China and Suman Fernando. 2014. "Globalizing Mental Health or Pathologizing the Global South? Mapping the Ethics, Theory and Practice of Global Mental Health." Disability and the Global South, 1(2): 188-202.

Morrison, Linda Joy. 2005. Talking Back To Psychiatry: The Psychiatric Consumer/Survivor/Ex-Patient Movement. New York, NY: Routledge. Oliver, Mike. 1992. "Changing the social relations of research production?" Disability, Handicap \& Society, 7(2), 101-114.

Parker, Ian. 1990. "Discourse: Definitions and Contradictions.” Philosophical Psychology, 3(2): 189-202.

Parker, Ian. 1992/2004. "Discovering Discourses, Tackling Texts.” Pp. 252 - 261 in Critical Strategies for Social Research, edited by W. K. Carroll. Toronto: Canadian Scholars' Press.

Parker, Ian. 2004. “Discourse Analysis.” Pp. 308-312 in A Companion to Qualitative Research, edited by U. Flick, E. von Kardorff and I. Steinke. London, UK: Sage Publications.

Pelletier, Jean-Francois, Alain Lesage, Andre Delorme, Ann C. Macaulay, Jonathan Salsberg, Catherine Vallée and Larry Davidson. 2011. "User-led Research: A Global and Person-Centered Initiative." International Journal of Mental Health Promotion, 13(1): 4-12.

Russo, Jasna. 2012. Survivor-controlled Research: A New Foundation for Thinking About Psychiatry and Mental Health. Forum: Qualitative Social Research 13(1): Art. 8.

Russo, Jasna and Peter Beresford. 2015. "Between exclusion and colonisation: seeking a place for mad people's knowledge in academia." Disability \& Society, 30(1): 153157.

Spandler, Helen, Jill Anderson and Bob Sapey. 2015. Madness, Distress and the Politics of Disablement. Bristol, UK: Policy Press. Sweeney, Angela. 2009. "So what is survivor research?” In This is Survivor Research, edited by Angela Sweeney, Peter Beresford, Alison Faulkner, Mary Nettle, and Diana Rose. Ross-on-Wye, UK: PCCS Books. 22 - 37.

Sweeney, Angela. 2016. "Why Mad Studies Needs Survivor Research and Survivor Research Needs Mad Studies." Intersectionalities, 5(3): 36-61.

Sweeney, Angela, Peter Beresford, Alison Faulkner, Mary Nettle, and Diana Rose, eds. 
2009. This is Survivor Research. Ross-on-Wye, UK: PCCS Books.

Turner, Michael and Peter Beresford. 2005. User Controlled Research: Its Meanings and Potential - Final Report. Shaping Our Lives and Centre for Citizen Participation, Brunel University. Commissioned by INVOLVE.

Wykes, Til. 2003. "Blue Skies in the Journal of Mental Health? Consumers in Research." Journal of Mental Health, 12(1): 1-6.

\section{Survivor research in Canada: 'Talking' recovery, resisting psychiatry, and reclaiming madness}

Points of interest

- Canadian psychiatric survivors have been leading many different kinds of research projects over the last twenty-five years. This is the first published study of Canadian survivor research.

- Canadian survivor research challenges what counts as evidence. These research projects used unconventional methods to find evidence that matters to psychiatric survivors. They argued for the importance of putting survivors in charge of all stages of the research process.

- Lots of these projects talked about recovery, but they used the word recovery in different ways. They tended to use the language of recovery in place of other more common words, such as 'mental illness'. Sometimes they used non-medical words such as madness and distress.

- This paper argues that Canadian survivor researchers should make it clear when they conduct survivor research. This will make it easier for people to find. 